\title{
BMJ Open Survey of community pharmacists' perception of electronic cigarettes in London
}

\author{
Ana C N Marques Gomes, Shereen Nabhani-Gebara, Reem Kayyali, \\ Federico Buonocore, Gianpiero Calabrese
}

To cite: Marques

Gomes ACN, NabhaniGebara S, Kayyali R, et al. Survey of community pharmacists' perception of electronic cigarettes in London. BMJ Open 2016;6:e013214.

doi:10.1136/bmjopen-2016013214

- Prepublication history for this paper is available online. To view these files please visit the journal online (http://dx.doi.org/10.1136/ bmjopen-2016-013214).

Received 28 June 2016 Revised 5 September 2016 Accepted 20 September 2016

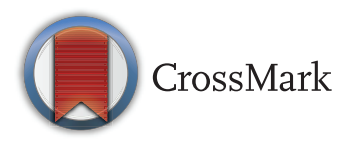

Department of Pharmacy, Drug Discovery, Delivery and Patient Care (DDDPC), School of Life Science, Pharmacy and Chemistry, Kingston University London, London, UK

Correspondence to Dr Gianpiero Calabrese; G.Calabrese@kingston.ac.uk

\section{ABSTRACT}

Objectives: To seek community pharmacists' perception on use, safety and possible effectiveness of e-cigarettes as quit smoking tools, and their future regulation.

Setting: A survey of a sample of 154 community pharmacies across London, UK.

Context: E-cigarettes have exclusively established themselves in the market through consumers-led demand. To date, e-cigarettes still remain unregulated and can be easily purchased in shops, over the internet, but more controversially also in pharmacies in the UK. Pharmacists find themselves with a shortage of information on their safety and efficacy, and may experience an ethical dilemma when consulted by patients/customers.

Key findings: Response rate: $60 \%(n=92)$. Independent pharmacies accounted for $90 \%$ of the sample. The majority of participants $(73 \%)$ sell e-cigarettes. A minority of participants $(20 \%)$ have been presented with adverse effects such as cough and dry mouth. As possible reasons for their use, pharmacists ranked 'aid in stop smoking' as the most important $(56 \%)$, with 'cheaper alternative' $(43 \%)$ and 'social/recreational use' ( $31 \%)$ being the least important ones. Safety issues were raised as statements such as 'e-liquid in cartridges may be toxic' were agreed by $52 \%$ of respondents. The majority of pharmacists $(97 \%)$ were supportive of e-cigarettes being regulated, expressing current concerns regarding excipients (42\%) and nicotine content $(34 \%)$. Participants indicated that they would require training in the form of information packs $(88 \%)$, online tutorials $(67 \%)$, continuous professional development (CPD) workshops (43\%) to cover safety, counselling, dosage instructions, adverse effects and role in the smoking cessation care pathway in the future. Conclusions: Pharmacists expressed concerns about the safety of e-cigarettes, especially regarding the amounts of excipients and nicotine as these still remain unregulated. Currently, there are no guidelines for pharmacists regarding e-cigarettes. Community pharmacists look forward to regulations so to conduct their duties in a more confident and legislated fashion.

\section{INTRODUCTION}

The e-cigarettes market has drastically increased with an estimated 1.3 million users

\section{Strengths and limitations of this study}

- This is the first study investigating the community pharmacists' perception on the use, safety and possible effectiveness of e-cigarettes as quit smoking tools, and their future regulation.

- Community pharmacists play an important role in the UK healthcare system as they work at the direct interface with patients and members of the public and due to their accessibility are often the first port of call for smoking cessation. Therefore, their perceptions about e-cigarettes may influence uptake and support.

- Despite having a substantial number of respondents, this study is limited to pharmacies in the Greater London area.

- Follow-up studies seeking community pharmacists' perception on a national scale may be needed to gauge concerns and to better inform regulators.

in the UK only: estimated to be worth $£ 340$ million by 2015. ${ }^{1}$ E-cigarettes have exclusively established themselves in the market through consumers-led demand. Their tar-free technology enlists their status as being 'safer' than conventional cigarettes, hence their evident peaking popularity. To date, e-cigarettes have ducked the advertising bans imposed on all tobacco products, even though broadcasts have in some occasions been perceived as 'glamorizing smoking and promoting e-cigarettes as a safe new lifestyle choice to young people'. ${ }^{2}$ E-cigarettes may in fact constitute a 'gateway' to smoking for nonusers of tobacco, especially adolescents. ${ }^{3-5}$ Coupled with the controversy regarding safety of the additives and flavours, healthcare professionals are still undecided regarding their use.

In 2013, the Medicines and Healthcare products Regulatory Agency (MHRA) announced that e-cigarettes will be regulated by $2016 ;{ }^{6}$ this was then followed by the European parliament voting for a dualsupply route: they could be regulated as 
either medicinal products (if marketed as quitting aids) or tobacco products. ${ }^{2}$ In the meanwhile, e-cigarettes remain unregulated products that can be easily purchased not only in shops, supermarkets and over the internet, but more controversially also in big chain ${ }^{7}$ and independent community pharmacies. Chief pharmaceutical officers in the UK unanimously expressed concern over pharmacies selling e-cigarettes ${ }^{8}$ warning pharmacy staff not to present e-cigarettes as having any therapeutic benefit until the MHRA licences individual e-cigarettes products. In the meanwhile, pharmacists shall continue advising patients on the benefits of using evidence-based products such as nicotine replacement therapies (NRTs), which have been tested and proved safe. In August 2015, a report commissioned by Public Health England indicated that e-cigarettes are around $95 \%$ safer than tobacco smoking as many chemicals present in smoke are absent in the e-cigarettes' vapours. ${ }^{9}$ In November of the same year, the MHRA in the UK licenced British American Tobacco's first-generation e-Voke.

While most of the works currently in the literature focus on the effectiveness of e-cigarettes, little can be found regarding how healthcare professionals perceive the current use, status and effectiveness of these devices. In an effort to assess the extent to which health professionals perceive e-cigarettes as a positive or negative development and needs for guidance, Hiscock et $a l^{10}$ surveyed 587 practitioners in 2011 and 705 in 2013. Despite the majority of respondents increasingly indicated e-cigarettes as a 'good thing', they found no clear evidence they viewed e-cigarettes having an important place in smoking cessation services. Practitioners still expressed concerns in terms of safety or efficacy of e-cigarettes for smoking cessation. Also, this study suggests that patients ask important questions about these products and practitioners felt that the guidance for staff and patients was not satisfactory. ${ }^{10}$ It is therefore unclear whether guidance currently provided to healthcare professional is satisfactory. To further feed this uncertainty, a survey ${ }^{11}$ of members of The British Thoracic Oncology Group showed that only a minority of respondents $(21.0 \%)$ were confident in providing advice to patients with lung cancer over the use of e-cigarettes, with nurses reporting lower levels of confidence.

In the literature, there is mixed evidence regarding the potential of e-cigarettes to serve as quit smoking aids. Etter $e t a l^{12}$ reported that e-cigarettes may contribute to prevention of relapse in former smokers and smoking cessation in current smokers, and they also showed that $81 \%$ of those vaping (ie, using e-cigarettes) daily were still vaping after 1 year. The latter datum indicates that people may end up replacing tobacco with ecigarettes, with still unclear, potential long-term exposure consequences. ${ }^{13}$ Siegel et $a l^{14}$ analysed abstinence rates via an online-based survey and reported that $48.8 \%$ of e-cigarette users achieved abstinence for a certain length of time and $34.3 \%$ reached complete abstinence at 6 months. More recently, Brown et al ${ }^{15}$ surveyed 5863 adults who had smoked within the previous 12 months and made at least one quit attempt during that period with either an e-cigarette only $(7.9 \%)$, over-the-counter NRT $(32.8 \%)$ or no aid $(59.3 \%)$. When measuring selfreported abstinence, they observed that the odds of nonsmoking in users of e-cigarettes were 1.63 times higher compared with users of NRT and 1.61 times higher compared with those using no aid. These results are remarkable because considering the large sample size of the study, it indicates that e-cigarettes may constitute a viable option for smokers to quit without the support of health professionals. Conversely, Bullen et $a l^{16}$ conducted a randomised controlled trial to evaluate e-cigarettes for smoking cessation against placebo e-cigarettes and patches and found that e-cigarettes were only 'modestly effective' at helping smokers to quit, with similar achievement of abstinence as with nicotine patches. In a 12-month randomised controlled trial on 300 smokers not intending to quit, Caponnetto et $a l^{17}$ documented smoking reduction in $22.3 \%$ and $10.3 \%$, and complete abstinence from tobacco smoking in $10.7 \%$ and $8.7 \%$ of participants at weeks 12 and 52, respectively. Additionally, Ling et $a l^{18}$ followed 949 people who reported their smoking habits through an online survey and 'found that there was no difference in the rate of quitting between smokers who used an e-cigarette and those who did not'.

The current General Pharmaceutical Council's position on the sale of e-cigarettes in registered pharmacies $^{19}$ and the Royal Pharmaceutical Society recommend that e-cigarettes should not be sold or advertised by pharmacies. ${ }^{20}$ There have been reports of pharmacists not adhering to this recommendation. ${ }^{21}$ The current lack of guidance on e-cigarettes for pharmacists and the mixed evidence regarding their efficacy may result in pharmacists having limited confidence in advising patients over the safety and efficacy of e-cigarettes. This work aims at exploring community pharmacists' perception on the use, safety and possible effectiveness of e-cigarettes as quit smoking tools, and their future regulation. We hypothesised that pharmacists have concerns regarding the safety of e-cigarettes and are in favour of future regulations, which will ensure patients' safety.

\section{METHOD}

This is a quantitative study involving a survey of community pharmacists in Greater London. Ethics approval was sought and obtained by the Kingston University Ethics Committee.

\section{Participants and recruitment}

Pharmacies were selected by convenience sampling to include small independent pharmacies and big chains. The selection of pharmacies was carried out without knowing whether e-cigarettes were sold on the premises. Pharmacists were approached in person or surveyed via mail. A maximum of two attempts were made to contact each pharmacy. Questionnaires delivered to pharmacies 
via mail services included a prepaid envelope for returning the questionnaire. When visiting pharmacies in person by a member of the research team, the options of 'wait and collect' and 'collect at later date' were offered to all pharmacists. Only fully completed questionnaires were considered for the study. Consent was obtained by means of an information letter accompanying the questionnaire outlining its aims and content, confidentiality, right to not participate or withdraw, as well as contacts of a minimum of three members of the research team. All respondents agreed to participate by returning a fully complete questionnaire. Only one response was received by each pharmacy.

\section{Questionnaire}

Data collection was performed using a paper-based questionnaire, consisting of 26 questions (4 of which on demographics). Question styles including closed, multiple response and open-ended questions were employed. In questions using a Likert scale, participants were asked to score statements on a five points scale, that is, ranging from 'very effective' to 'totally ineffective' or from 'strongly agree' to 'strongly disagree'. The questions contained in this research tool were developed by the authors in collaboration with undergraduate students. The themes were identified following a previous survey conducted by the same team (unpublished) aimed at establishing the aspects of e-cigarettes which members of the public hoped to find out more about. As a consequence, the questionnaire was structured in six sections. Section A aimed at surveying the current use of any smoking cessation programme and NRTs available on premises. Section B questioned respondents on the current experience with e-cigarettes (eg, whether e-cigarettes were sold on premises and adverse effects presented by users). Questions in Sections C and D aimed at gauging the pharmacists' perception of use, safety and effectiveness, and of regulations of e-cigarettes, respectively. Section $\mathrm{E}$ was regarding the type and content of potential training on e-cigarettes for pharmacists. Section F contained questions on demographics.

\section{Pilot study}

After ethics approval, a pilot study was conducted with five pharmacists for content and face validation. The outcomes of the pilot indicated that the questionnaire was suitable for pharmacy professional, presented a sensible number of questions which could be completed within a reasonable time, and required some minor amendments of questions. The pharmacists involved in the pilot were then excluded from the study to avoid any type of bias.

\section{Data analysis}

Analysis of data was performed using Microsoft Excel. Descriptive statistics were used to describe and summarise the data highlighting the basic features of the study. When analysing the responses, in questions regarding the perception of safety and effectiveness of e-cigarettes which were based on a Likert scale, the options 'strongly agree' and 'agree' as well as 'disagree' and 'strongly disagree' were, respectively, grouped together. Open-ended questions were not analysed as these were not compulsory and only a minority of respondents added comments.

\section{RESULTS}

\section{Response rate and demographics}

A total of 154 questionnaires were distributed across all areas of London. From these, 92 questionnaires were fully completed and returned. This resulted in an overall $60 \%$ response rate. The demographics of the population are summarised in table 1 . On analysis of results, no statistically relevant variation in responses was observed when considering demographic data.

\section{E-cigarettes users profile}

E-cigarettes were shown to be sold on the premises of $73 \%(\mathrm{n}=67)$ of community pharmacies responding to the study. The majority of pharmacists identified the most common form was nicotine-containing e-cigarettes $(97 \%, \mathrm{n}=65)$. The most common age group to be identified as purchasing e-cigarettes according to community pharmacists was the '25-40 years old' $(90 \%, \mathrm{n}=60)$, with equal popularity among ' $18-24$ ' and ' $41-55$ years old' (each $4 \%, \mathrm{n}=3$ ). Adverse effects were presented to only $20 \%(\mathrm{n}=19)$ of community pharmacists. Of these, $17 \%$ $(\mathrm{n}=16)$ were 'rarely' presented with side effects and $3 \%$ $(n=3)$ of respondents described the frequency as 'sometimes'. Side effects reported to pharmacists included

\begin{tabular}{|c|c|c|}
\hline & Number (n) & Percentage (\%) \\
\hline \multicolumn{3}{|l|}{ Job type } \\
\hline Full time & 45 & 48.9 \\
\hline Part time & 5 & 5.5 \\
\hline Locum & 34 & 36.9 \\
\hline Superintendents & 3 & 3.2 \\
\hline Managers & 5 & 5.5 \\
\hline \multicolumn{3}{|l|}{ Location } \\
\hline North & 17 & 18.5 \\
\hline South & 17 & 18.5 \\
\hline East & 40 & 43.5 \\
\hline West & 18 & 19.5 \\
\hline \multicolumn{3}{|c|}{ Years of practice (since registration) } \\
\hline $0-5$ & 27 & 29.3 \\
\hline $6-10$ & 36 & 39.1 \\
\hline $11-15$ & 15 & 16.3 \\
\hline $16-20$ & 5 & 5.5 \\
\hline$>20$ & 9 & 9.8 \\
\hline \multicolumn{3}{|l|}{ Gender } \\
\hline Male & 61 & 66.3 \\
\hline Female & 31 & 33.7 \\
\hline
\end{tabular}


Table 2 Community pharmacists' perception of reasons behind the use of e-cigarettes

\begin{tabular}{|c|c|c|c|c|c|c|c|c|c|c|}
\hline & \multicolumn{2}{|c|}{$\begin{array}{l}\text { Aid in stop } \\
\text { smoking }\end{array}$} & \multicolumn{2}{|c|}{$\begin{array}{l}\text { Use in } \\
\text { public } \\
\text { places }\end{array}$} & \multicolumn{2}{|c|}{$\begin{array}{l}\text { Prevent } \\
\text { relapse }\end{array}$} & \multicolumn{2}{|c|}{$\begin{array}{l}\text { Cheaper } \\
\text { alternative }\end{array}$} & \multicolumn{2}{|c|}{$\begin{array}{l}\text { Social/ } \\
\text { recreational } \\
\text { use }\end{array}$} \\
\hline & $\mathrm{n}$ & $\%$ & $\mathbf{n}$ & $\%$ & $\mathbf{n}$ & $\%$ & $\mathbf{n}$ & $\%$ & $\mathbf{n}$ & $\%$ \\
\hline Ranked 1 (most important) & 47 & 55.9 & 5 & 6.0 & 28 & 33.3 & 2 & 2.4 & 2 & 2.4 \\
\hline Ranked 2 & 25 & 29.8 & 8 & 9.5 & 33 & 39.3 & 5 & 6.0 & 13 & 15.5 \\
\hline Ranked 3 & 10 & 11.9 & 24 & 28.6 & 9 & 10.7 & 16 & 19.0 & 25 & 29.8 \\
\hline Ranked 4 & 1 & 1.2 & 30 & 35.7 & 11 & 13.1 & 25 & 29.8 & 18 & 21.4 \\
\hline Ranked 5 (least important) & 1 & 1.2 & 17 & 20.2 & 3 & 3.6 & 36 & 42.8 & 26 & 30.9 \\
\hline Total & 84 & 100 & 84 & 100 & 84 & 100 & 84 & 100 & 84 & 100 \\
\hline
\end{tabular}

cough $(n=10)$, dry mouth $(n=7)$, sore throat $(n=3)$ and headache $(\mathrm{n}=1)$.

Respondents were required to rank ' 1 ' (the most important) to ' 5 ' (the least important) the reasons why users choose e-cigarettes. Some respondents $(9 \%, n=8)$ could not answer the question, due to lack of awareness of the subject. From the remaining pharmacists $(n=84)$, its use as an 'aid in stop smoking' was ranked as the most important (' 1 ') by $56 \%(\mathrm{n}=47)$. The use in 'prevent relapsing' was ranked as ' 2 ' $(39 \%, \mathrm{n}=33)$, whereas being a 'cheaper alternative' was ranked as ' 5 ' $(43 \%, \mathrm{n}=36)$, thus deemed as the least important. Results are summarised in table 2.

\section{Pharmacists' perception of effectiveness and safety}

Participants were asked to rate the effectiveness of e-cigarettes as a smoking cessation tool as compared to NRTs and other support. Results are summarised in table 3.

In regard to 'e-cigarettes are safe to inhale', most community pharmacists showed no opinion $(52 \%, \mathrm{n}=47)$. The majority of pharmacists $(60 \%, \mathrm{n}=65)$ disagreed with the statement "e-cigarettes do not cause any adverse effects'. With regard to 'manufacturing of e-cigarettes is unreliable', half of the participants $(51 \%, \mathrm{n}=46)$ were found to agree. Similarly, the following two statements 'e-cigarette encourages smoking in non-smokers' and 'e-liquid in cartridges may be toxic' found respondents in agreement with $58 \%(\mathrm{n}=52)$ and $61 \%(\mathrm{n}=55)$, respectively. For 'the design of e-cigarettes encourage smokers to give up smoking', a significant majority $(81 \%, \mathrm{n}=73)$ agreed with it. Responses are summarised in figure 1.

\section{Pharmacists' perception of regulations}

Overall, 97\% ( $n=89)$ of respondents were in support of future regulations of e-cigarettes. For the $97 \%$ who were supportive, further potential benefits were rated. The main benefits (rated ' 5 , extremely beneficial') were 'reassured safety for e-cigarette users' and 'regulated as an established NRT for smoking cessation', with $72 \% \quad(\mathrm{n}=64)$ and $55 \%(\mathrm{n}=49)$, respectively. With regard to 'preventing the misuse of illegal substances' and 'increased profit for retail pharmacy', responses were more normally distributed as summarised in figure 2.

All community pharmacists were required to choose one aspect of e-cigarettes which they perceive should be more tightly regulated. Excipients were selected by $42 \%$ $(n=37)$ of participants, nicotine concentration by $34 \%$ $(n=30)$, followed by eligibility and accessibility at $10 \%$ $(n=9)$ and $9 \%(n=8)$, respectively. Also, results from the survey show that $63 \%(n=58)$ of pharmacists think that the main disadvantages arising from the new regulation will be the generation of a 'black market'.

\section{Training needs}

Out of all responses, $83 \%(\mathrm{n}=76)$ of community pharmacists stated that they were ready to stock and supply e-cigarettes in their pharmacy, under new regulations. To evaluate the perception of required training to meet

Table 3 Perception of the effectiveness of e-cigarettes in smoking cessation

\begin{tabular}{|c|c|c|c|c|c|c|c|c|c|c|}
\hline & \multicolumn{2}{|c|}{$\begin{array}{l}\text { Classic NRTs } \\
\text { (eg patch) }\end{array}$} & \multicolumn{2}{|c|}{$\begin{array}{l}\text { Newer NRTs } \\
\text { (eg Quickmist) }\end{array}$} & \multicolumn{2}{|c|}{ E-cigarettes } & \multicolumn{2}{|c|}{$\begin{array}{l}\text { GP and } \\
\text { pharmacist } \\
\text { counselling }\end{array}$} & \multicolumn{2}{|c|}{$\begin{array}{l}\text { Family and } \\
\text { support group }\end{array}$} \\
\hline & $\bar{n}$ & $\%$ & $\bar{n}$ & $\%$ & $\bar{n}$ & $\%$ & $\bar{n}$ & $\%$ & $\bar{n}$ & $\%$ \\
\hline Very effective & 34 & 36.9 & 42 & 45.6 & 18 & 19.6 & 41 & 44.6 & 30 & 32.6 \\
\hline Effective & 45 & 48.9 & 41 & 44.6 & 39 & 42.4 & 31 & 33.7 & 26 & 28.3 \\
\hline Slightly effective & 12 & 13.1 & 8 & 8.7 & 22 & 23.9 & 18 & 19.5 & 24 & 26.1 \\
\hline Somewhat ineffective & 1 & 1.1 & 1 & 1.1 & 8 & 8.7 & 2 & 2.2 & 11 & 11.9 \\
\hline Totally ineffective & - & - & - & - & 2 & 2.2 & - & - & 1 & 1.1 \\
\hline Unsure & - & - & - & - & 3 & 3.2 & - & - & - & - \\
\hline Total & 92 & 100 & 92 & 100 & 92 & 100 & 92 & 100 & 92 & 100 \\
\hline
\end{tabular}




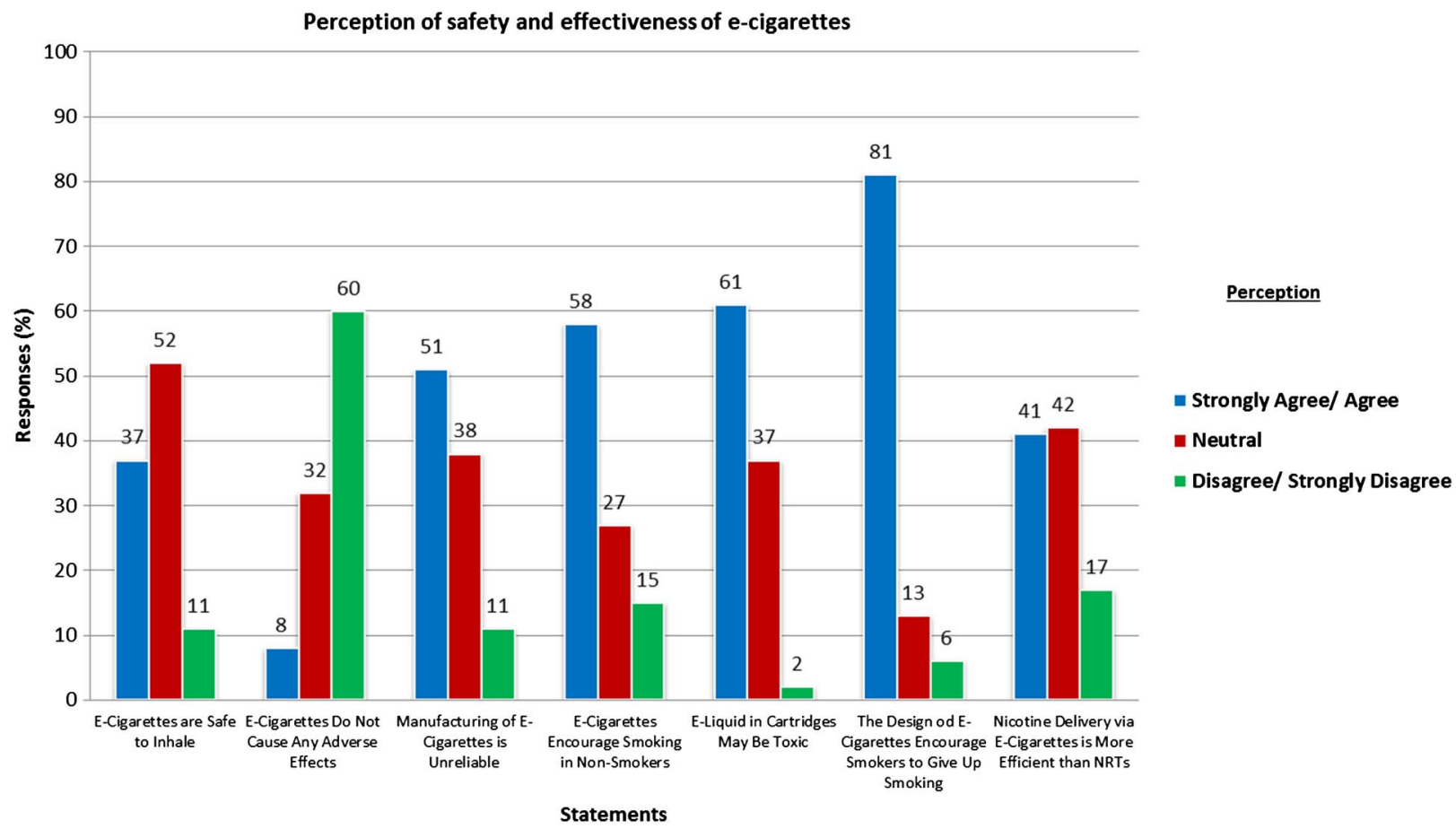

Figure 1 Perception of the safety and effectiveness of e-cigarettes.

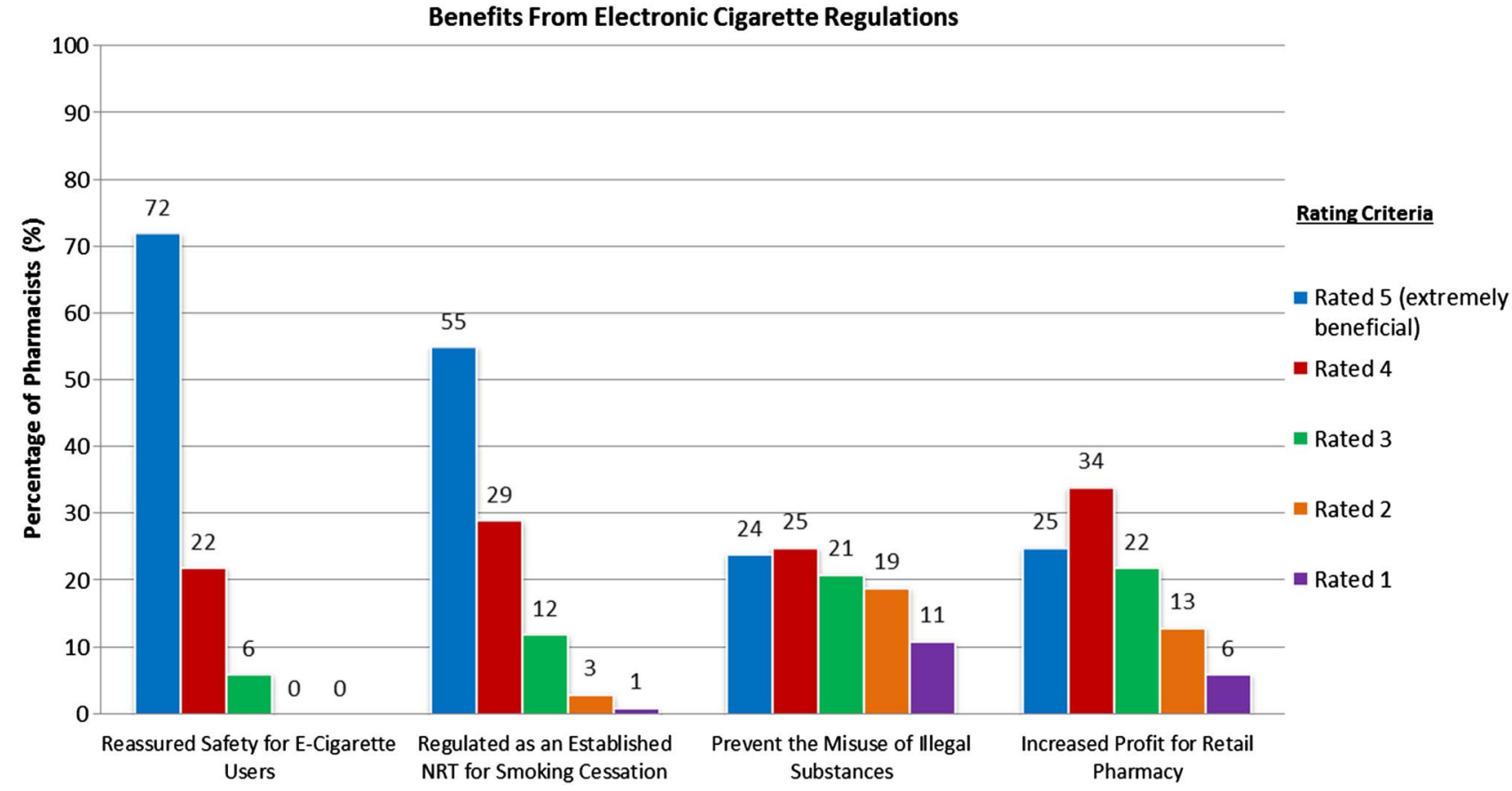

Figure 2 Perception of potential benefits stemming from e-cigarettes regulations.

potential future MHRA regulations on e-cigarettes, all participants were asked to indicate the likely form and content of training packages. Considering that each participant could tick as many options as appropriate, information packs were the most popular $(88 \%, \mathrm{n}=67)$, followed by online tutorials at $67 \%(\mathrm{n}=51)$, and professional developments workshops and video tutorials at $43 \%(\mathrm{n}=33)$ and $33 \%(\mathrm{n}=25)$, respectively. Participants were also asked to score ( 1 to 10 , with 10 being the most important) the likely content of training packages. A median grading analysis showed that safety was scored in all cases as the most important (10 out of 10). Counselling information, dosage instructions and dealing with adverse effects had an average of 9 out of 10 , whereas implementation into cessation programmes scored 8 out of 10 . 


\section{DISCUSSION}

Three-quarters of participants indicated e-cigarettes to be sold on their premises. This demonstrates that many pharmacies do not adhere with the current General Pharmaceutical Council's and the Royal Pharmaceutical Society's recommendations for pharmacies not to sell and advertise e-cigarettes. ${ }^{19}{ }^{20}$ The majority of respondents are from small independent pharmacies, which may have been driven to the decision of selling e-cigarettes following major pharmacy chains doing so in the UK. ${ }^{7}$ The most popular form of e-cigarettes is the nicotine-containing one $(97 \%, \mathrm{n}=65)$. This popularity is most probably due to the need to relieve craving and consistent with the outcomes of the trial conducted by Dawkins $e t a l,{ }^{22}$ which consisted of 86 smokers being randomised to nicotine-containing (18 mg) e-cigarettes, placebo or device given to hold. The outcomes indicated that after $20 \mathrm{~min}$, the use of nicotine-containing e-cigarettes was superior in terms of relieving cravings.

The possibility of adverse effects was highlighted as one of the primary reasons for enforcing e-cigarette regulations for the safety of users. However, respondents reported to be not commonly presented with adverse effects as the vast majority of them chose 'never' when asked about user's reports. Etter et $a l^{23}$ reported $21 \%$ of e-cigarette users who stopped using e-cigarettes due to the fear of e-cigarette-induced side effects, whereas Goniewicz et $a l^{24}$ had only 17 (out of 179) users reporting adverse effects. The most common adverse effect reported by community pharmacists was 'cough'. Polosa et $a l^{25}$ classified this frequent adverse effect as being a result towards secondary exposure to humectants used within e-liquid formulations. The excipient propylene glycol has also been established to cause irritations through inhalation. Headache and cough are also reported as very common side effect of the use of e-Voke.

More than half of the pharmacists perceived users turn to e-cigarettes as an 'aid in stop smoking'. This is supported further by $44 \% \quad(n=39)$ of respondents who rated e-cigarettes as being 'effective' in promoting smoking cessation. These views seem to be in line with the perception of users who indicated to be using e-cigarettes because they were safer than tobacco and to quit smoking. ${ }^{23}$ Correlations can also be based on perceptions of community pharmacists on the 'design of e-cigarettes encouraging smokers to give up smoking', in which $62 \%(n=56)$ chose 'agree', hence concluding that the design of e-cigarettes is an effective characteristic in promoting cessation as this targets the stimulus attachment a smoker has. ${ }^{26}$

With regard to preventing relapse, the majority of respondents $(42 \%, \mathrm{n}=38)$ chose 'neutral' and $27 \%$ $(n=25)$ chose 'agree' for the statement 'nicotine delivery via e-cigarettes is more efficient than NRTs'. In addition to this, e-cigarettes were perceived as effective as classic NRTs (ie, patch, gum) and the newer NRTs (ie, Quickmist, inhalator). In a 6-month study, ${ }^{16}$ abstinence was compared between a nicotine patch and an e-cigarette. The trial concluded with $7.3 \%$ attaining abstinence through optimising an e-cigarette and $5.8 \%$ attained abstinence through a NRT patch. Thus, this shows the potential of e-cigarettes to attain increased cessation numbers, which can be based on their ability to provide nicotine through the same route as conventional cigarettes. It is also noted that in comparison to pharmacological tools, psychological support from 'general practitioners and pharmacist counselling' is also perceived as 'very effective' according to $45 \%$ $(\mathrm{n}=41)$.

In relation to 'social/recreational use', $31 \%(n=26)$ of respondents ranked this as the least important for usage of e-cigarettes. However, aspects of social and recreational use can be determinant when non-smokers are attracted to the vaping community. Regarding the statement 'e-cigarettes encourages smoking in non-smokers', almost half of respondents chose 'agree'. According to Bell and Keane, ${ }^{27}$ this promotes a negative opinion regarding e-cigarettes and furthermore fears of uncontrolled use in non-smokers and in young adolescents.

Safety was a key concern expressed notably by community pharmacists within this study. Participants revealed concerns regarding the verified safety of e-cigarettes. In regard to 'e-cigarettes are safe to inhale', the majority either chose 'neutral' or 'strongly agreed/agreed'. This correlates to perceptions relating to 'e-cigarettes do not cause any adverse effects', in which $60 \%$ chose 'disagree/strongly disagree' and for 'e-liquid in cartridges may be toxic', where $61 \%$ chose 'strongly agreed/ agreed'. This is in line with the concerns expressed by smoking cessation practitioners and reported by Hiscock et $a l^{10}{ }^{10}$ The evidentiary confirmation on negative perceptions on safety can also be linked to requests by respondents of stricter regulations being imposed on excipients. In line with respondents' perception of e-cigarettes on safety, half of the community pharmacists chose 'strongly agree/agree' for the statement 'manufacturing of e-cigarettes is unreliable'. Chen ${ }^{28}$ and Avdalovic and Murin ${ }^{29}$ have related these types of perspectives to the unregulated procedures of manufacturing, including being below standards of optimal quality, reduced quality control and insufficient evidence to assure safety.

The concern on safety has been prevalent on the support for regulations to be imposed in order to control aspects of e-cigarettes. The support of MHRA regulations to become obligatory was almost a unanimous consent in this study. Expressed opinions by many included 'to fully ensure the content in an e-cigarette do not interact with patient medications', 'if available on NHS then it is more for reaching' and 'gives us as pharmacists the opportunity to engage those purchasing these items, the same we would do with our regular customers'. These perceptions enhance the hopes of community pharmacists to be more proactive in smoking cessation while ensuring patient safety under enforced 
regulations. From those in support of regulations, major benefits were significantly rated for 'reassured safety for e-cigarette users' and for e-cigarettes to be 'regulated as an established NRT for smoking cessation'. Conversely, those who were against regulations were primarily due to perceptions on e-cigarettes being a tobacco product, that is, 'e-cigarettes are made by tobacco companies and secondly it does not encourage you to quit at all'. This type of perception can be the direct consequence of the indecisiveness occurring in the EU parliament (and MHRA) on regulations and e-cigarettes as being produced by tobacco companies, hence placing doubts on e-cigarettes being a candidate to meet the criteria of being a 'medicine'.

Respondents were further asked to choose one aspect of e-cigarettes, which they felt should be more tightly regulated. Excipients were selected by almost half of the respondents, hence hinting the need for regulations to ensure quality assurance and safety by manufacturers. 'Nicotine concentration' was instead selected by $34 \%$ $(n=30)$ of the respondents, ensuring that concentrations do not lead to increased dependence or fatal toxicities.

Community pharmacists were also asked if they were ready to stock and supply under future regulations. The vast majority of respondents felt they were ready, hence confirming that community pharmacists are more comfortable to supply under enforced regulations. Despite e-Voke has been licenced as NRT, to date, there has not been an organised statement from the regulators as to the role of e-cigarettes in smoking cessation nor a guidance to the community pharmacists at the forefront of this issue.

\section{CONCLUSIONS}

This study was implemented in order to gain an understanding of the community pharmacists' perceptions of e-cigarettes in terms of safety, reason for use, effectiveness and regulations. The concerns outlined include risks of unregulated excipients, faulty manufacturing leading to suboptimal quality, uncontrolled concentrations of nicotine and risks of adverse effects. In contrast, e-cigarettes were distinguished as being an ideal candidate as an effective tool for cessation, distinctively supported by respondents. With the majority wishing to stock and supply e-cigarettes under enforced regulations, it is clear that community pharmacists believe e-cigarettes can play a significant role in affording smoking abstinence and are ready to take new steps into achieving higher quitting rates in smoking cessation. The perceptions of community pharmacists are based prominently on ensuring the upmost care and safety for their patients. For these reasons, it is recommended that regulations, other than on ad hoc basis as it has happened for e-Voke, are introduced in the near future. This study is limited to a relatively small number of pharmacies in the Greater London area; a similar study on national scale is recommendable as its outcomes may give a more general perception of e-cigarettes by community pharmacists and gather useful information for regulators. With the effects of control in conjunction with implementation of the pharmacist's role in an effective guidance, it is believed by many that e-cigarettes do have a future within the community pharmacy.

\section{Twitter Follow Shereen Nabhani-Gebara at @shereenabhani}

Contributors GC is the principal investigator of the study. He is responsible for the design of the study, and organised and coordinated all aspects of the research including all steps of the manuscript preparation. ACNMG has drafted the publication and co-led the investigation. FB has contributed to the analysis of results. SN-G and RK have actively helped the provision of data collection tool and analysis of results.

Funding This study was supported by the Department of Pharmacy at Kingston University, London.

Competing interests None declared.

Ethics approval Kingston University Ethical Committee.

Provenance and peer review Not commissioned; externally peer reviewed.

Data sharing statement No additional data are available.

Open Access This is an Open Access article distributed in accordance with the Creative Commons Attribution Non Commercial (CC BY-NC 4.0) license, which permits others to distribute, remix, adapt, build upon this work noncommercially, and license their derivative works on different terms, provided the original work is properly cited and the use is non-commercial. See: http:// creativecommons.org/licenses/by-nc/4.0/

\section{REFERENCES}

1. Bauld L, Angus K, de Andrade M. E-cigarette uptake and marketing. A report commissioned by Public Health England. https://www.gov.uk/government/uploads/system/uploads/ attachment_data/file/311491/Ecigarette_uptake_and_marketing.pdf (accessed May 2016).

2. Sukkar E. Debate over e-cigarettes heats up as European parliament tightens rules. PJ Online 2014;292:223-4.

3. Sutfin EL, McCoy TP, Morrell HER, et al. Electronic cigarette use by college students. Drug Alcohol Depend 2013;131:214-21.

4. Pepper JK, Reiter PL, McRee AL, et al. Adolescent males' awareness of and willingness to try electronic cigarettes. $J$ Adolescent Health 2013;52:144-50.

5. Cho JH, Shin E, Moon SS. Electronic-cigarette smoking experience among adolescents. J Adolescent Health 2011;49:542-6.

6. Medicines and Healthcare products Regulatory Agency (MHRA). Press release: UK moves towards safe and effective electronic cigarettes and other nicotine-containing products. 2013 [3 screens]. http://www.firstwordpharma.com/node/1106890\#axzz4AFJhMInP (accessed May 2016).

7. The Royal Pharmaceutical Society. Boots and Lloydspharmacy join the vaping fold by selling e-cigarettes. PJ Online 2014. http://www. pharmaceutical-journal.com/news-and-analysis/news/boots-andlloydspharmacy-join-the-vaping-fold-by-selling-e-cigarettes/ 11134333.article (accessed May 2016).

8. Ridge KW. A matter of concern. Opinion/letter section. PJ Online 2014;292:473.

9. McNeill A, Brose LS, Calder R, et al. E-cigarettes: an evidence update. A report commissioned by Public Health England. https:// www.gov.uk/government/uploads/system/uploads/attachment_data/ file/457102/Ecigarettes_an_evidence_update_A_report commissioned_by_Public_Health_England_FINAL.pdf (accessed Aug 2016).

10. Hiscock R, Goniewicz ML, McEwen A, et al. E-cigarettes: online survey of UK smoking cessation practitioners. Tob Induc Dis 2014;12:13.

11. Sherratt FC, Newson L, Field JK. Electronic cigarettes: a survey of perceived patient use and attitudes among members of the British thoracic oncology group. Respir Res 2016;17:55.

12. Etter JF, Bullen C. A longitudinal study of electronic cigarettes users. Addict Behav 2014;39:491-4. 
13. McCauley L, Markin C, Hosmer D. An unexpected consequence of electronic cigarette use. Chest 2012;141:1110-3.

14. Siegel MB, Tanwar KL, Wood KS. Electronic cigarettes as a smoking-cessation tool: results from an online survey. $A m$ $J$ Preventative Med 2011;40:472-5.

15. Brown J, Beard E, Kotz D, et al. Real-world effectiveness of e-cigarettes when used to aid smoking cessation: a cross-sectional population study. Addiction 2014;109:1531-40.

16. Bullen $\mathrm{C}$, Howe $\mathrm{C}$, Laugesen $\mathrm{M}$, et al. Electronic cigarettes for smoking cessation: a randomised controlled trial. Lancet 2013;382:1629-37.

17. Caponnetto $\mathrm{P}$, Campagna $\mathrm{D}$, Cibella $\mathrm{F}$, et al. EffiCiency and safety of an eLectronic cigAreTte (ECLAT) as tobacco cigarettes substitute: a prospective 12-month randomized control design study. PLoS One 2013;8:e66317.

18. Grana RA, Popova L, Ling PM. A longitudinal analysis of electronic cigarette use and smoking cessation. JAMA Intern Med 2014:174:812-3.

19. http://www.pharmacyregulation.org/gphc-outlines-position-sale-ecigarettes-registered-pharmacies. 2014 (accessed May 2016).

20. http://www.rpharms.com/what-s-happening-/news_show.asp? id=1099. 2014 (accessed May 2016).

21. Weinbren E, Sisodia P. Pharmacists defy RPS call to halt e-cigarette sales; http://www.chemistanddruggist.co.uk/news-content/-/article_ display_list/17515397/pharmacists-defy-rps-call-to-halt-e-cigarettesales. 2014 (accessed May 2016).
22. Dawkins L, Turner J, Hasna S, et al. The electronic-cigarette: effects on desire to smoke, withdrawal symptoms and cognition. Addict Behav 2012;37:970-3.

23. Etter JF, Bullen C. Electronic cigarette: users profile, utilization, satisfaction and perceived efficacy. Addiction 2011;106:2017-28.

24. Goniewicz ML, Lingas EO, Hajek P. Patterns of electronic cigarette use and user beliefs about their safety and benefits: an internet survey. Drug Alcohol Rev 2013;32:133-40.

25. Polosa R, Caponnetto P, Morjaria JB, et al. Effect of an electronic nicotine delivery device (e-cigarette) on smoking reduction and cessation: a prospective 6-month pilot study. BMC Public Health 2011;11:1-12.

26. Wynn WP, Stroman RT, Almgren MM, et al. The pharmacist "toolbox" for smoking cessation a review of methods, medicines, and novel means to help patients along the path of smoking reduction to smoking cessation. J Pharm Pract 2012;25:591-9.

27. Bell K, Keane H. Nicotine control: e-cigarettes, smoking and addiction. Int J Drug Policy 2012;23:242-7.

28. Chen IL. FDA summary of adverse events on electronic cigarettes. Nicotine Tob Res 2013;15:615-6.

29. Avdalovic MV, Murin S. Electronic cigarettes: no such thing as a free lunch...or puff. Chest 2012;141:1371-2.

30. Cancer Research UK. E-cigarettes - the unanswered questions. 2013. http://scienceblog.cancerresearchuk.org/2013/05/30/ e-cigarettes-the-unanswered-questions/ (accessed May 2016). 